\title{
Shock Index In Obstetric Hemorrhage As An Applicable Method To Anticipate Adverse Outcome
}

Hend S. Saleh ( $\nabla$ drhendsaleh@yahoo.com )

Zagazig University https://orcid.org/0000-0001-7584-5241

Entesar R.Mahdy

Zagazig University

Ahmed H Elsayad

Zagazig University

Eman M.Mahfouz

Zagazig University

Ahmed Mahmoud Abdou

Zagazig University

Mohamed El-Husseny Radwan

Zagazig University

Hala E Sherif

Zagazig University

Research Article

Keywords: Postpartum haemorrhage, shock index, vital signs, hypovolaemic shock

Posted Date: December 20th, 2021

DOI: https://doi.org/10.21203/rs.3.rs-150063/v2

License: (c) (7) This work is licensed under a Creative Commons Attribution 4.0 International License. Read Full License 


\section{Abstract}

Background: To establish the ability of shock index and the different vital signs to predict the adverse maternal outcomes in the cases of obstetric hemorrhage

Methods: This prospective - retrospective study comprised patients with primary PPH or hemorrhage due to obstetric cause who were referred to zagazig University hospital Egypt , from January 2018, to December 2019 Data of vital signs of them ; systolic and diastolic blood pressure, pulse rate, pulse pressure, mean arterial pressure and shock index (heart rate divided by systolic blood pressure) at time of arrival were investigated . Adverse outcome like, death , admission to the intensive care unit, massive transfusion and invasive procedures were revised and analyzed. AUROC (area under the receiver operating characteristic curve ) was used for shock index in comparison to each vital sign for predicting the adverse maternal outcomes. Sensitivity, specificity, and negative and positive predictive values were assessed to detect the best predictor.

Results: The mean age of participants years (SD)was $29.2( \pm 7.3)$ of admission and $44 \%$ had altered. The most Common cause of hemorrhage was latrogenic ; either misuse of uterotonic or traumatic $30.2 \%$

The mean value of HR 108.1 \pm 26.6 , SBP $101 \pm 28.7 \mathrm{mmHg}$, DBP $58.9 \pm 21.3 \mathrm{mmHg}, \mathrm{SI} 1.153 \pm 0.541$ and mean blood loss 1922 (0.862) .For death, SI and SBP had the highest AUC value at $0.88(0.81-0.95)$ with $\mathrm{P}=0.213)$. For ICU blood transfusion $\geq 5 \mathrm{iu}$, admission and invasive surgical interventions, SI had the uppermost AUROC value at $0.76,0.78$ and 0.61 . Sensitivity for all adverse outcomes of $\mathrm{SI} \geq 0.7$,is $\mathrm{h}$ from 99 to 90.0 . For death prediction $\mathrm{SI} \geq 0.7$ had very low specificity $; 0.6\{0.2-1.3\}$ and of $\mathrm{SI} \geq 0.9 ; 6.4\{2.8-7.1\}$

Conclusion: Shock index is a strapping applicable predictor of adverse outcomes. for patients who suffering from hypovolemic shock due to obstetric hemorrhage,

\section{Background}

Universally, Haemorrhage due to obstetric cause remains the foremost reason of maternal morbidity and mortality $99 \%$ of them happen in low- and middleincome countries .1 The primary condition of women with obstetric hemorrhage may be recognized by the quantity of blood . 2 Visual estimation of blood loss was recommended as the standard for blood loss measurement by WHO although it may be underestimated by up to $33 \%-50 \%$ before the transferal and even after the arrival of the patient.3Assessment of pregnant ladies with an emergency like hemorrhage outside facilities, with inexpert or no assistants and delaying of transportation due to referral difficulties, increases the incidence of adverse outcomes .4 The basic strategy to reduce that haemorrhagerelated outcomes is early recognition, rapid intervention, and well-timed referral.5 As, Visual estimation of blood loss miscalculates thus, vital signs like systolic blood pressure. (SBP) and heart rate (HR) are used to evaluate haemodynamic stability .6

During pregnancy and postpartum, there are haemodynamic changes which may postponement the detection of hypovolaemia .Blood pressure falls when pregnant females lose around $30 \%$ of their blood volume, But at the time of severe bleeding the sympathetic tone is activated instantly to keep the blood pressure and so, the heart rate is increased over blood. 7 Consequently, The shock index (SI) which was estimated as HR/SBP, has been suggested as an former indicator of compromise than conventional vital signs in non-pregnant people .8,9. SI has also been planned as a dependable marker of compromise In an obstetric residents. 10 . It has been suggested that; normal SI in non-pregnant people $0.5-0.7 \quad 11$ and SI $\geq 0.9$ matches with high incidence of mortality and morbidity.12 "shock index alterations, reflect the hemodynamic response to blood loss and announce the occurrence of adverse maternal outcomes".13

Another a significant predictor of maternal adverse outcome is coagulopathy, Nevertheless, it frequently yields $\geq 30$ minutes to get the results, Also, the samples of blood may coagulate easier when there is not enough blood of the sample like in the case of hypovolemia associated with obstetric hemorrhage and so delaying in management .14

Few studies have assessed SI as a marker to predict adverse outcomes in referred patients suffering from Postpartum or obstetric hemorrhage. So, The current study was designed to evaluate SI and the other vital signs, as predictor markers of different adverse maternal outcomes amongst patients with obstetric hemorrhage that were referred to our tertiary hospital .

\section{Methods}

It is a prospective -retrospective study of 242 ladies admitted with postpartum hemorrhage( $\mathrm{PPH}$ ) to obstetric emergency unit at zagazig University tertiary hospital, Egypt from January 2018, to December 2019. Approval on the study was taken from the institutional committees of Zagazig University Hospital . Informed written or thumbprint consent was taken from All women or their relatives if they were unconscious or confused at time of admission . Participation of Women was depended on reaching to level of valued blood loss $>750 \mathrm{ml}$ and systolic blood pressure (SBP) $<100 \mathrm{~mm} \mathrm{Hg}$ and/or pulse rate $>100$ beat /minute(BPM)

Predictor variables involved, Vital signs; \{pulse, SBP, diastolic blood pressure (DBP), mean arterial pressure $(\mathrm{MAP}=(2 \times \mathrm{DBP}+\mathrm{SBP}) / 3), \mathrm{SI}(\mathrm{pulse} / \mathrm{SBP})$, and pulse pressure (SBP-DBP). Automated blood pressure device or auscultatory technique with mercury sphygmomanometer was used to measure blood preasure .\} and shock index (heart rate divided by systolic blood pressure) were documented at 15 minute breaks, till the source of bleeding was found and managed as patient became vitally stable (SBP $\geq 100 \mathrm{~mm} \mathrm{Hg}$, pulse rate $\leq 100 \mathrm{BPM}$ ) for at least 2 hours, and blood loss had declined to almost $25-50 \mathrm{~mL}$ per hour.

Severe shock at study entry was defined as MAP $<60 \mathrm{mmHg}$, as perfusion of blood to vital organs has been probably affected $.15 T h e$ lower verge of the shock index was choiced as $\geq 0.7$ that was identified as the higher edge of normal shock index in a non-pregnant People,2 and $\geq 0.9$ as the upper one of 
normal Instant postpartum.16,17 The management was primarily with ordinary practice comprising intravenous hydration, manual massages, ice packs and \or uterotonics,

Adverse maternal outcomes like ; death, , ICU admission,ICU admission massive blood transfusion and critical interventions outcome including blood transfusion $\geq 5$ units , admission atintensive care unit, or emergency hysterectomy were documented all .Data were analyzed with SPSS version 19.0 (IBM, Chicago, IL, USA) and MedCalc 16.4.1 (MedCalc Software bvba, Ostend, Belgium). Calculation of Sensitivities, specificities, and positive and negative predictive values was done. Differences were considered statistically significant at $\mathrm{P}<0.05$.

\section{Results}

242 women were women referred to our hospital due to obstetric haemorrhage Demographics criteria of the participants at the stage of study entrance are presented in Table 1 . The mean age of participants years (SD)was $29.2( \pm 7.3) .56 \%$ of the participants were alert at time of admission and $44 \%$ had altered consciousness. The most Common cause of hemorrhage was latrogenic; either misuse of ecopolics or traumatic $30.2 \%$ then uterine atony ( $29.1 \%$ ) and last cause was molar pregnancy complications $0.7 \%$.

Table 2 ; represents the (mean \pm SD ) values of vital signs of the participants. The mean value of HR 108.1 $\pm 26.6, \mathrm{SBP} 101 \pm 28.7 \mathrm{mmHg}, \mathrm{DBP} 58.9 \pm 21.3$ $\mathrm{mmHg}$, SI $1.153 \pm 0.541$ and mean blood loss 1922 (0.862). Table 3 shows the performance of SI(Shock index) and other vital sign parameter in predicting the adverse clinical outcomes. For death, SI and SBP had the highest AUC value at $0.88(0.81-0.95)$ with $P=0.213$. and significantly higher than pulse rate $(p=0.031)$ and pulse pressure $(p=0.022)$. As regard ICU admission, It had the uppermost AUROC value at $0.76(0.64-0.88)$ which was significantly higher than for SBP $(P=0.024)$, DBP $(P=0.012)$, MAP $(P=0.024)$, and $P P(P=0.002)$, But, pulse rate $(P R)(P=0.818)$ is not significantly higher than $\mathrm{SI}($ Shock index ). About blood transfusion $\geq 5 \mathrm{iu}, \mathrm{SI}$ had the highest AUROC 0.78 , which was significantly higher than for $\mathrm{SBP}(\mathrm{P}=0.034), \mathrm{DBP}(\mathrm{P}=0.029)$, $\operatorname{MAP}(P=0.025)$, and more significant than pulse pressure $(p=0.001)$ but not that of pulse rate $(P=0.708)$,

For invasive surgical interventions, the shock index hadthe highest AUROC value at $0.61(0.46-0.79$ whichwas statistically, not significantly higher than for systolic BP $(P=0.074)$, diastolic $\mathrm{BP}$, heart rate or $\operatorname{MAP}(P=0.289, P=0.472$ and $\mathrm{p}=0.344$, respectively $)$. But it had significant difference more than pulse pressure $(P=0.0411)$.

Table 4 shows the convenience of $\mathrm{SI} \geq 0.7$ and $\mathrm{SI} \geq 0.9$ as early predictors of adverse outcome of postpartum haemorhage . Of the 242 women encompassed in This study, there were $212(88 \%)$ with $\mathrm{SI} \geq 0.7$ and $133(55 \%)$ with $\mathrm{SI} \geq 0.9$. Sensitivity for all adverse outcomes of $\mathrm{SI} \geq 0.7$,is $\mathrm{h}$ from 99 to 90.0 . which is high specifying that approximately all positives are exactly recognized as such while several negatives are categorized as false positives . For death prediction $\mathrm{SI} \geq 0.7$ had very low specificity $; 0.6\{0.2-1.3\}$ and of $\mathrm{SI} \geq 0.9 ; 6.4\{2.8-7.1\}$

As all of the women in the study had hypovolemic shock, the high rate of positive test results is clinically acceptable

\section{Discussion}

The current study evaluates the role of shock index as an indicator for prediction of adverse outcome in patients referred due to obstetric hemorrhage in Comparison with other vital signs. Numerous studies have investigated the efficiency of the shock index in PPH like Nathan et al. 18 who established that, comparing it with further vital signs,. He found that SI and HR were significantly better predictors than all other vital signs For ICU admission, but for transfusion $\geq 4 \mathrm{iu}$, SI had the highest AUROC value, performing significantly better than HR .Lee et al 201819 found that; The shock index was ominously useful for prediction of massive transfusion but for invasive procedures and ICU admission; shock index and pulse rate had higher AUROC values than blood pressure.

Our study established that; SI for ICU and massive blood transfusion $\geq 5$ iu had more significant prediction than SBP $(0.024,0.034)$, DBP $(0.012,0.029)$, MAP $(0.02,0.025)$ and $\mathrm{PP}(0.002,0.001)$. As regard the pulse rate; SI had the same significance .About surgical interference; SI had more significance than SBPand PP $(0.07,0.041)$ and the same significancy of DBP , PR and MAP .

Sohn et al.20 stated that the shock index is a predictor of massive bleeding and the initial shock index is individualistically associated with massive transfusion.13, but they did not study other adverse outcomes, for example ICU admission or invasive procedures .and These results are similar to those results of Nathan et al 18 .Predictable vital signs have been revealed to be late markers of haemodynamic Compromise in obstetric and even non- obstetric people.SI may aid Observing such cases with modify management to reduce the adverse outcomes via resuscitation and referral at time.

The current study examined the performance of the upper limits of $\mathrm{SI} \geq 0.7$ and $\mathrm{SI} \geq 0.9$. Lee et al suggested that $\mathrm{SI} \geq 0.9$ expects adverse events like massive transfusion and invasive procedures So, can take right decisions of the management (time and type). This agreed with our results. El Ayadi et al 21 found that $\mathrm{SI} \geq 0.9$ indicates a need for referral, as their this study was directed in a low-resource setting where necessary resuscitation for emergency patients with obstetric hemorrhage are insufficient or suboptimal; consequently, the results can be generalized to our communities

\section{Conclusion}

Shock index is a strapping applicable predictor of adverse outcomes for patients who suffering from hypovolemic shock due to obstetric hemorrhage, and $\mathrm{SI} \geq 0.9$ Specifying the need for referral to tertiary place or rough nursing inside tertiary care.

\section{Limitations}


our interpretations are limited to a somewhat small sample that means need to a large one to nbe studied in the future. The protocol of management pre referral was different thus the outcome of patients might be affected.

\section{Recommendations}

Prospective studies on large number of patients suffering from obstetric haemorrhage is required to optimally appreciate the value of the shock index mainly in low source outcome setting

\section{Abbreviations}

$\mathrm{PPH}$ : primary PPH or hemorrhage

AUROC : area under the receiver operating characteristic curve

SI: Shock Index

SBP : systolic blood pressure

DBP : diastolic blood pressure

MAP : mean arterial pressure

ICU : Intensive care unit

$\mathrm{PP}$ : pulse pressure

$\mathrm{PR}$ : pulse rate

\section{Declarations}

\section{Disclosure}

The contents of this publication are solely the responsibility of the authors.

\section{Ethics approval and consent to participate}

Not applicable

\section{Consent for publication}

Not applicable.

\section{Availability of data and materials}

The dataset for the current study is available from the corresponding author upon receipt of a reasonable request .

\section{Competing interests}

The authors declare they have no competing interests.

\section{Funding}

The author received no specific funding for this work, it was self-supported, with no support provided by any funding agency.

\section{Authors' Contributions}

The all authors confirm full responsibility for study conception and design, analysis and interpretation of results, and manuscript preparation. Also ,All authors were involved in developing and drafting the manuscript. The final version is read and approved by all authors.

\section{Acknowledgements}

Not Applicable

\section{Conflicting of interests}

The authors declare they have no conflict of interests.

\section{References}


1 Say L, Chou D, Gemmill A, Tunc_alp €O, Moller A-B, Daniels J, et al. Global causes of maternal death: a WHO systematic analysis. Lancet Glob Health 2014;2:e323-33.

2 World Health Organization. WHO Recommendations for the Prevention and Treatment of Postpartum Haemorrhage. Geneva: WHO; 2012.

3 Schorn MN. Measurement of blood loss: Review of the literature. J Midwifery Womens Health. 2010;55:20-27.9

4-World Health Organisation. The World Health Report 2005: Make Every Mother and Child Count. Geneva: World Health Organization, 2005.

5 -World Health Organisation. World Health Organisation Guidelines for the Management of Postpartum Haemorrhage and Retained Placenta. Report of a Technical Working Group, Geneva: World Health Organisation, 2009..

6- Schorn MN. Measurement of blood loss: review of the literature. J Midwifery Womens Health 2010;55:20-7.

7- Rath WH. Postpartum hemorrhage-update on problems of definitions and diagnosis. Acta Obstet Gyneco/ Scand. 2011;90: 421-428. 8

8- Allgower MBC. Shock index. Dtsch Med Wochenschr 1967;92:1947-50.

9- Troiano NH, Harvey CJ, Chez BF. AWHONN High-Risk \& Critical Care Obstetrics. Mandeville: Lippincott Williams \& Wilkins; 2012

10-Pacagnella RC, Souza JP, Durocher J, Perel P, Blum J, Winikoff B,et al. A systematic review of the relationship between blood loss and clinical signs. PLoS One 2013;8:e57594.

11 Rady MY, Nightingale P, Little RA, Edwards JD. Shock index: a re-evaluation in acute circulatory failure. Resuscitation 1992;23:227-34.

12 -Vandromme MJ, Griffin RL, Kerby JD, McGwin G Jr, Rue LW 3rd, Weinberg JA. Identifying risk for massive transfusion in the relatively normotensive patient: utility of the prehospital shock index. J Trauma 2011;70:384-8;discussion 8-90.

13.- Ryan KL, Rickards CA, Hinojosa-Laborde C, Cooke WH, ConvertinoVA. Sympathetic responses to central hypovolemia: New insights from microneurographic recordings. Front Physiol. 2012;3:110.

14.- Oh KJ, Hong JS, Youm J, Cho SH, Jung EY. Can coagulopathy in post-partum

hemorrhage predict maternal morbidity? J Obstet GynaecolRes. 2016;42:1509-1518.

15. McAuley DF. The Clinician's Ultimate Reference-Mean Arterial Pressure. GlobalRPh Inc.; 2005; Available: http://www.globalrph.com/map.htm. Accessed 28 October 2008.

16-Le Bas A, Chandraharan E, Addei A, Arulkumaran S. Use of the "obstetric

shock index" as an adjunct in identifying significant blood loss in patients with massive postpartum hemorrhage. Int J Gynecol Obstet. 2014;124:253-255.

17.-Rady MY, Nightingale P, Little RA, Edwards JD. Shock index: A re-evaluation in acute circulatory failure. Resuscitation. 1992;23:227-234.

18. Nathan HL, El Ayadi A, Hezelgrave NL, et al. Shock index: An effective

predictor of outcome in postpartum haemorrhage? BJOG. 2015;122:268-275.

19 - Lee S Young, Kim H Yeon, Cho Geum-Joon, Hong S Cheol Jeong O Min, Kim H Joong Use of the shock index to predict maternal outcomes in women referred for postpartum hemorrhage . 2018; Int J Gynecol Obstet 1-4

20- Sohn CH, Kim WY, Kim SR, et al. An increase in initial shock index is associated with the requirement for massive transfusion in emergency department patients with primary postpartum hemorrhage. Shock. 2013;40:101-105

21-El Ayadi AM, Nathan HL, Seed PT, et al. Vital sign prediction of adverse maternal outcomes in women with hypovolemic shock: The role of shock index. PLoS ONE. 2016;11:e0148729.

\section{Tables}

Table (1): Characteristics of Participants 


\begin{tabular}{|c|c|c|}
\hline Character & $\mathbf{N}(242)$ & $\%$ \\
\hline Age & $29.2(7.3) \mathrm{a}$ & \\
\hline \multicolumn{3}{|l|}{ Parity } \\
\hline PO & & 3.4 \\
\hline P1 & & 10.1 \\
\hline P2 & & 36.2 \\
\hline$P \geq 3$ & & 50.3 \\
\hline Body mass Index (BMI ) & $27.3(4-7)$ & \\
\hline \multicolumn{3}{|l|}{ level of consciousness } \\
\hline alert & & 56 \\
\hline altered & & 44 \\
\hline \multicolumn{3}{|l|}{ Mode of delivery } \\
\hline Vaginal & 39.1 & \\
\hline Caesarean section & 60.9 & \\
\hline \multicolumn{3}{|l|}{ Obstetric causes } \\
\hline latrogenic & 73 & 30.1 \\
\hline Misuse of ecopolics & 48 & 19.8 \\
\hline Traumatic & 25 & 10.3 \\
\hline Atonic & 70 & 28.9 \\
\hline Placenta aacreta & 41 & 16.9 \\
\hline Placenta previa & 29 & 12 \\
\hline Ectopic & 21 & 8.6 \\
\hline Abortion & 6 & 2.4 \\
\hline Molar pregnancy & 3 & 1.2 \\
\hline
\end{tabular}

Values presented as Mean (SD) , N=number or \%= percentage

Table 2 (Mean \pm SD) Values of different vital signs

\begin{tabular}{|ll|}
\hline Variable & Value \\
\hline Shock Index (SI) & $0.541 \pm 1.153$ \\
\hline Pulse rate, beats per min & $26.6 \pm 108.1$ \\
\hline Systolic blood pressure (SBP)mmHG & $28.7 \pm 101.8$ \\
\hline Diastolic blood pressure (DBP) mmHG & $\pm 21,358.9$ \\
\hline Mean blood loss ml (SD) & $1922(0.862)$ \\
\hline
\end{tabular}

Table 3 Performance of SI(Shock index) and various vital signs using AUROC in predicting mortality and adverse clinical outcome amongst ladies suffered from obstetric hemorhage . 


\begin{tabular}{|c|c|c|c|c|c|c|c|c|c|c|c|}
\hline \multirow[b]{2}{*}{$\begin{array}{l}\text { Adverse clinical } \\
\text { outcome }\end{array}$} & \multicolumn{10}{|l|}{ Vital sign } & \multirow{2}{*}{$\begin{array}{l}P \\
\text { value }\end{array}$} \\
\hline & $\begin{array}{l}\text { (ShockSI } \\
\text { index) }\end{array}$ & $\begin{array}{l}\text { (SystolicSBP } \\
\text { ) BP }\end{array}$ & $\begin{array}{l}P \\
\text { value }\end{array}$ & $\begin{array}{l}\text { (DiastolicDBP } \\
\text { BP) }\end{array}$ & $\begin{array}{l}P \\
\text { value }\end{array}$ & rate) (Pulse PR & $\begin{array}{l}P \\
\text { value }\end{array}$ & $\begin{array}{l}\text { (MAP } \\
\text { mean } \\
\text { arterial } \\
\text { pressure) }\end{array}$ & $\begin{array}{l}P \\
\text { value }\end{array}$ & $\begin{array}{l}\text { (PulsePP } \\
\text { Pressure) }\end{array}$ & \\
\hline Death & $\begin{array}{l}0.88(0.81- \\
0.95)\end{array}$ & $\begin{array}{l}0.89(0.82- \\
0.96)\end{array}$ & 0.213 & $\begin{array}{l}0.80(0.70- \\
0.91)\end{array}$ & 0.201 & $\begin{array}{l}0.79(0.68- \\
0.88)\end{array}$ & 0.031 & $\begin{array}{l}0.84(0.78- \\
0.92)\end{array}$ & 0.132 & $\begin{array}{l}0.38(0.27- \\
0.52)\end{array}$ & 0.022 \\
\hline I CU admission & $\begin{array}{l}0.76(0.64- \\
0.88)\end{array}$ & $\begin{array}{l}0.74(0.65- \\
0.84)\end{array}$ & 0.024 & $\begin{array}{l}0.65(0.46- \\
0.85)\end{array}$ & 0.012 & $\begin{array}{l}0.64(0.45- \\
0.83)\end{array}$ & 0.818 & $\begin{array}{l}0.65(0 . \\
45-0.84)\end{array}$ & 0.024 & $\begin{array}{l}0.56(0.41- \\
0.68)\end{array}$ & 0.002 \\
\hline $\begin{array}{l}\text { Blood } \\
\text { 5iu } \geq \text { transfusion }\end{array}$ & $\begin{array}{l}0.78(0.72- \\
0.82)\end{array}$ & $\begin{array}{l}0.70(0.65- \\
0.74)\end{array}$ & 0.034 & $\begin{array}{l}0.71(0.64- \\
0.74)\end{array}$ & 0.029 & $\begin{array}{l}0.81(0.77- \\
0.84)\end{array}$ & 0.708 & $\begin{array}{l}0.71(0.66- \\
0.77)\end{array}$ & $\begin{array}{l}0 . \\
025\end{array}$ & $\begin{array}{l}0.49(0.46- \\
0.57)\end{array}$ & 0.001 \\
\hline $\begin{array}{l}\text { Invasive surgical } \\
\text { intervention }\end{array}$ & $\begin{array}{l}0.61(0.46- \\
0.79)\end{array}$ & $\begin{array}{l}0.59(0.47- \\
0.81)\end{array}$ & 0.074 & $\begin{array}{l}0.56(0.41- \\
0.76)\end{array}$ & 0.289 & $\begin{array}{l}0.58(0.37- \\
0.78)\end{array}$ & 0.472 & $\begin{array}{l}0.57(0.36- \\
0.61)\end{array}$ & 0.344 & $\begin{array}{l}0.49(0.37- \\
0.61)\end{array}$ & 0.041 \\
\hline
\end{tabular}

AUROC,(95\% confidence interval). area under the receiver operating characteristic curve; ICU, intensive care unit;

Table 4. showed the predictive value of shock indexes of $\geq 0.7$ and $\geq 0.9$

\begin{tabular}{|c|c|c|c|c|c|}
\hline Outcomes & SI & Sensitivity $(95 \% \mathrm{Cl})$ & $\begin{array}{l}\text { Specificity } \\
(95 \% \mathrm{Cl})\end{array}$ & $\begin{array}{l}\text { Positive } \\
\text { predictive } \\
\text { value }(95 \% \mathrm{Cl})\end{array}$ & $\begin{array}{l}\text { Negative predictive } \\
\text { value }(95 \% \mathrm{Cl})\end{array}$ \\
\hline \multirow[t]{2}{*}{ Death } & $\mathrm{SI} \geq 0.7$ & $99.0\{91-100\}$ & $0.6\{0.2-1.3\}$ & $5.0\{1.9-4.6\}$ & $99.5\{38.7-99.8\}$ \\
\hline & $S I \geq 0.9$. & $99.0\{91-99\}$ & $6.4\{2.8-7.1\}$ & $5.6\{2.8-4.9\}$ & $99.6\{93.7-98.9\}$ \\
\hline \multirow[t]{2}{*}{ Icu admission } & $S I \geq 0.7$ & $98.0\{78-98.1\}$ & $13.2\{9.8-18.7\}$ & $7.1\{2.9-11.1\}$ & $99.8\{87.2-100\}$ \\
\hline & $S I \geq 0.9$ & $97.0\{79.3-99.8\}$ & $41.2\{32.7-49.2\}$ & $9.1\{3.9-13.9\}$ & $99.6\{95.1-100\}$ \\
\hline \multirow[t]{2}{*}{ Massive Blood transfusion } & $\mathrm{SI} \geq 0.7$ & $93.0\{80-97.0\}$ & $16.3\{11.2-20.7\}$ & $19.1\{12.8-23.8\}$ & $89.9\{76.1-97.8\}$ \\
\hline & $S I \geq 0.9$ & $81.0-\{66.6-92.8\}$ & $43.5\{36.1-48.9\}$ & $22.6\{17.1-30.9\}$ & $90.8\{84.1-95.8\}$ \\
\hline Invasive surgical & $S I \geq 0.7$ & $90.2\{60.7-98.5$ & $13.9\{8.9-18.8\}$ & $6.1\{3.1-10.1\}$ & $97.1\{82.7-98.8\}$ \\
\hline intervention & $\mathrm{SI} \geq 0.9$ & $85.6\{52.5-96.1\}$ & $41.9\{36.1-48.9\}$ & $8.1\{4.2-12.9\}$ & $98.2\{91.8-99.6\}$ \\
\hline
\end{tabular}

